\title{
A Clinical Study of Anterior Uveitis in a Rural Hospital
}

\author{
Dr.Anitha.S.Maiya ${ }^{1}$, Dr.Sundip Shenoy ${ }^{2}$ \\ 1,2 (Department of Ophthalmology/Adichunchanagiri Institute of Medical Sciences/RGUHS/India)
}

\begin{abstract}
Background: Uveitis is a complex intraocular inflammatory disease that results from several aetiological entities. Anterior uveitis is the most common form of uveitis and is commonly seen in young adults. This study was undertaken to evaluate the modes of presentation, aetiology and complications of anterior uveitis among the rural population. Methods: a prospective clinical study was conducted in the Department of Ophthalmology, Adichunchanagiri Institute of Medical Sciences, B.G.Nagara. All patients aged between 20-80 years who presented with anterior uveitis were studied. A comprehensive ophthalmic evaluation followed by relevant laboratory investigations were done to determine the aetiology. Patients were put on nonspecific and appropriate specific treatment and followed up. Response to treatment and any complications developing during the course were noted. Results: Anterior uveitis occurred most commonly in the 30-40 years age group $(35 \%)$. Majority of the cases had nongranulomatous inflammation(95\%) and aetiology remained unknown in $40 \%$ of the cases. Most common cause was blunt trauma(20\%) followed by phacolytic uveitis (15\%). Most cases responded favourably to medical management. Conclusions: In a majority of the cases, the aetiology of anterior uveitis remains undetermined. A tailored battery of investigations based on age, history and clinical findings are needed to facilitate a final diagnosis. Prompt and early treatment ensures good visual outcome. Regular follow up is needed for early detection of ocular and systemic complications that may occur secondary to the cause of uveitis or its treatment.
\end{abstract}

Keywords: anterior uveitis, blunt trauma, nongranulomatous inflammation, phacolytic uveitis.

\section{Introduction}

Uveitis is an inflammatory condition of the uveal tract and adjacent structures that affects mainly children and young adults. It includes a large group of intraocular inflammatory diseases of diverse etiology. On several occasions, it reflects diseases developing elsewhere in the body and uveitis may be the first evidence of such systemic disease[1]. It has been quoted that uveitis accounts for $0.8 \%$ of hospital outpatient visits [2].

Anterior uveitis is the most common form of uveitis (accounts for $57.4 \%$ of uveitic entities). The annual incidence of anterior uveitis is about 8 cases per 1,00,000 population [3].

The precise cause of anterior uveitis is often obscure and the correct diagnosis is often challenging. The cause of inflammation may be infectious agents (exogenous or endogenous) or trauma, but in most cases the underlying mechanism appears to be autoimmune in nature [4].

As per the recommendations of the International Uveitis Study Group(IUSG), anterior uveitis is categorised into iritis (inflammation of the iris), anterior cyclitis( inflammation of the anterior portion of ciliary body) and iridocyclitis (inflammation of iris and ciliary body). Patients with anterior uveitis present with redness of the eyes, photophobia, watering of eyes and blurred vision. [5]

Anterior uveitis causes vision loss both directly due to inflammation and via complication such as secondary glaucoma, cataract, macular edema, retinal detachment and others. The treatment of uveitis itself can result in ocular and systemic complications $[6,7,8]$.

Anterior uveitis can generally be managed by medical therapy and surgical interventions are only needed if structural complications like cataract supervene. Since the aetiology of uveitis is usually unknown or no specific treatment is available in many cases despite definitive diagnosis, non specific measures are employed. This includes, Corticosteroids (ocular, periocular and/or systemic), topical cycloplegic drugs, Non Steroidal Anti-Inflammatory drugs (NSAIDs) and immunosuppressive drugs $[9,10,11,12]$.

Although anterior uveitis is the most easily managed form of uveitis, the ocular morbidity associated with it is moderately high.

This study was undertaken to evaluate the modes of presentation, aetiology and complications of anterior uveitis among the rural population.

\section{Materials And Methods}

A prospective clinical study was conducted in the Department of Ophthalmology, Adichunchanagiri Institute of Medical Sciences, B.G.Nagara after obtaining clearance from the Institutional Ethics Committee. Consecutive patients aged between 20 to 80 years who were clinically diagnosed to have anterior uveitis were included in the study after obtaining an informed consent. 
Anterior uveitis following penetrating ocular injuries, corneal ulcer, recent intraocular surgeries and those associated with intermediate, posterior or panuveitis were excluded from the study.

A standard clinical proforma was used in all cases, which included detailed ocular and systemic history, visual acuity assessment using Snellen's chart, clinical findings, laboratory investigations and the final aetiological diagnosis. All patients underwent a comprehensive ocular examination which included visual acuity assessment, detailed slit lamp examination, IOP measurement (by Goldmann Applanation Tonometer) and posterior segment examination.

The inflammation was considered acute if symptoms were present for less than 3 months, chronic if symptoms were present for more than 3 months and recurrent if the patient had two or more episodes of inflammation separated by a disease free period.

A short differential diagnosis was made in each case and tailored laboratory investigations were carried out. Investigations including total and differential WBC counts, Erythrocyte sedimentation rate,blood sugar levels, urine and stool examination, Mantoux test and serological tests for Toxoplasmosis, Syphilis, HIV, Rheumatoid factor were done in all cases. X-ray of chest, knee and lumbosacral joints were done. Other investigations like HLA-B27, ANA and Angiotensin-converting enzyme levels were done whenever necessary.

Final aetiological diagnosis was made based on history, clinical features, laboratory investigations and systemic evaluation by other medical specialities.

All patients were treated medically wtih topical steroids (Prednisolone acetate $1 \%$ or Fluorometholone) and topical cycloplegics (Atropine eye ointment or Homatropine eye drops). the frequency of steroids was titrated according to the severity of uveitis and gradually tapered according to the clinical response.

Specific therapy (eg. Systemic antivirals) were given whenever aetiology was known. Systemic and/or periocular steroids were reserved for severe cases and those not adequately responding to topical therapy. Patients with lens induced inflammation underwent cataract surgery after inflammation was reasonably controlled medically. Patients with secondary glaucoma were treated medically with T.Acetazolamide $250 \mathrm{mg}$ TID for3-5 days and Timolol $0.5 \%$ eye drops BID.

All the patients were followed up and response to treatment and complications were recorded.

\section{Results}

A total of 20 patients with anterior uveitis aged between 20-80 years were studied and the following observations were made:

Table 1. Age wise distribution of cases

\begin{tabular}{|c|c|l|}
\hline Age (years) & Number of patients & Percentage \\
\hline $21-30$ & 1 & 5 \\
\hline $31-40$ & 7 & 35 \\
\hline $41-50$ & 1 & 5 \\
\hline $51-60$ & 4 & 20 \\
\hline $61-70$ & 5 & 25 \\
\hline $71-80$ & 2 & 10 \\
\hline
\end{tabular}

Table 2. Gender distribution, presenting symptoms, type of onset, laterality and type of inflammation.

\begin{tabular}{|c|c|c|}
\hline & Number of cases & Percentage \\
\hline \multicolumn{3}{|c|}{ Sex wise distribution of cases } \\
\hline Male & 12 & 60 \\
\hline Female & 8 & 40 \\
\hline \multicolumn{3}{|c|}{ Common presenting symptoms of anterior uveitis } \\
\hline Redness of eyes & 16 & 80 \\
\hline Pain & 16 & 80 \\
\hline Watering & 9 & 45 \\
\hline Dimunition of vision & 10 & 50 \\
\hline \multicolumn{3}{|l|}{ Clinical presentation } \\
\hline Acute & 16 & 80 \\
\hline Chronic & 3 & 15 \\
\hline Recurrent & 1 & 5 \\
\hline \multicolumn{3}{|c|}{ Laterality of Anterior uveitis } \\
\hline Unilateral & 19 & 95 \\
\hline Bilateral & 1 & 5 \\
\hline
\end{tabular}

In this study, 16 patients (80\%) had nongranulomatous inflammation and 4 patients $(20 \%)$ had granulomatous inflammation. Of the 4 cases of granulomatous uveitis, 2 were due to Herpes zoster ophthalmicus and 2 were detected to be secondary to tuberculosis. 
Table 3. Aetiological distribution of cases.

\begin{tabular}{|l|c|c|}
\hline Aetiology & Number of cases & Percentage \\
\hline Idiopathic & 8 & 40 \\
\hline Blunt trauma & 4 & 20 \\
\hline Phacolytic & 3 & 15 \\
\hline Herpes zoster ophthalmicus & 2 & 10 \\
\hline Tuberculosis & 2 & 10 \\
\hline Iridocyclitis associated with arthritis & 1 & 5 \\
\hline
\end{tabular}

In the present study, all the 20 patients were treated with topical steroids and cycloplegics. Two patients required systemic steroids(both patients had phacolytic uveitis and had severe postoperative inflammation). The two patients of Herpes zoster were treated with oral Acyclovir for 10 days. The two patients with secondary glaucoma responded to topical antiglaucoma medications and did not need any surgical intervention. The three cases of phacolytic uveitis underwent small incision cataract surgery with implantation of posterior chamber intraocular lens.

Graph 1. Complications of anterior uveitis
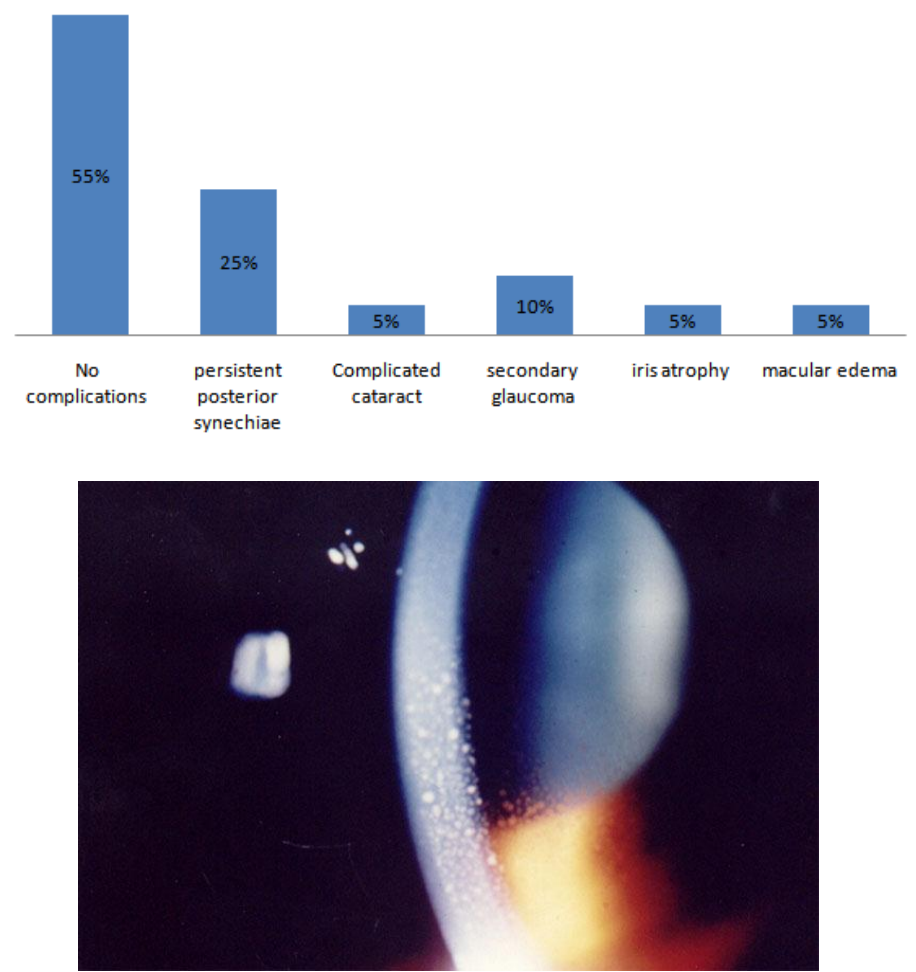

Fig1. Small to medium sized keratic precipitates on the corneal endothelium in non granulomatous anterior uveitis.

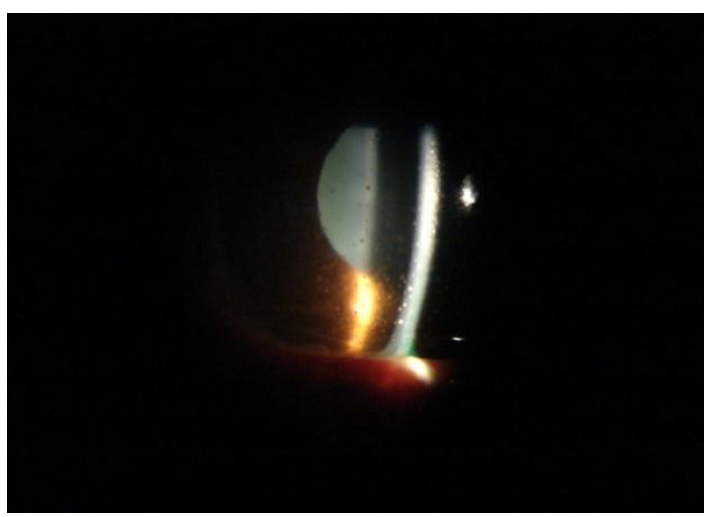

Fig 2. Large mutton fat keratic precipitates in granulomatous anterior uveitis. 


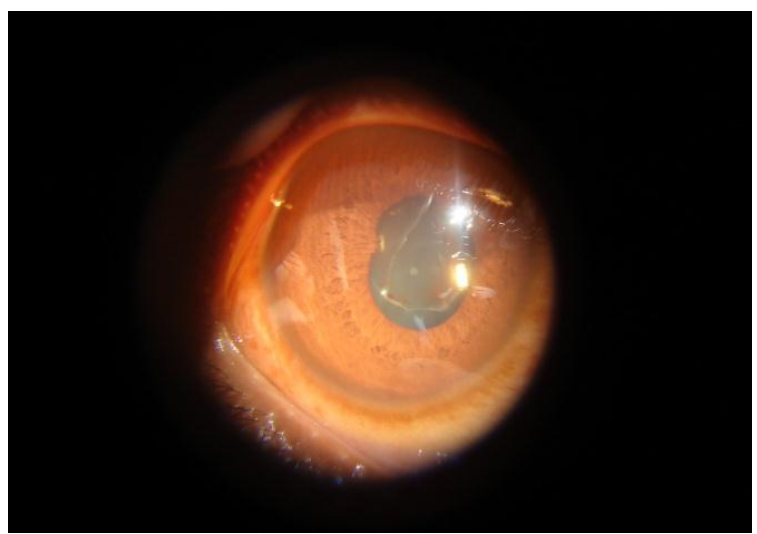

Fig 3. Persistent posterior synechiae

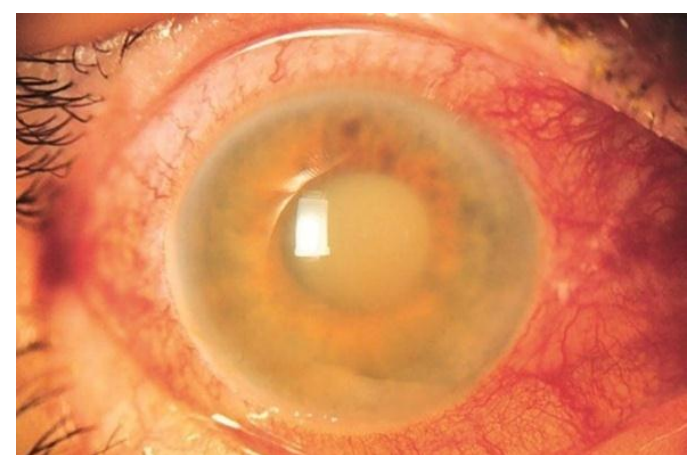

Fig 4. Phacolytic uveitis.

\section{Discussion}

The present study was conducted in the Department of Ophthalmology, Adichunchanagiri Institute of Medical Sciences, B.G.Nagara and 20 cases of anterior uveitis were studied.

The incidence was high in the 31-40 years age group (35\%) followed by the 61-70 years age group $(25 \%)$. It was observed that males were affected more (60\%) as compared to females (40\%). In the study by Rathinam SR, $61.3 \%$ were males and $38.7 \%$ were females[2]. In the study by Alezandro Rodriguez et al, gender distribution was $38.9 \%$ males and $61.1 \%$ females[13]. The most common symptoms with which the patients presented were redness of eye and pain ( $80 \%$ of patients).

The most common presentation was acute iridocyclitis ( $80 \%$ of patients) followed by chronic (in $15 \%$ of patients. Recurrent anterior uveitis was seen in only one patient who was detected to be positive for HLAB27 antigen and is presently on immunosuppressant drugs. In the study by Rathinam SR et al, $71.9 \%$ of cases had acute anterior uveitis, $24.3 \%$ were chronic and 3.8\% were recurrent anterior uveitis [2]. Majority of the patients had unilateral anterior uveitis (95\% of patients) without significant predeliction for either right eye or left eye. This corresponds with the study by Rathinam SR et al in which majority $(85.3 \%)$ had unilateral anterior uveitis. Majority of the cases had nongranulomatous inflammation which corresponds with two other previous studies[2,13].

Table 4. Comparison of aetiological factors of present study with other studies.

\begin{tabular}{|l|l|l|l|l|}
\hline Aetiology & Present study(\%) [n=20] & $\begin{array}{l}\text { Rathinam SR[2](\%) } \\
{[\mathrm{n}=5028]}\end{array}$ & $\begin{array}{l}\text { Singh et al[14](\%) } \\
{[\mathrm{n}=607]}\end{array}$ & $\begin{array}{l}\text { Henderly et al[15](\%) } \\
{[\mathrm{n}=167]}\end{array}$ \\
\hline Idiopathic & 40 & 44.6 & 61.3 & 43.52 \\
\hline Blunt trauma & 20 & 7.7 & - & 2.52 \\
\hline Phacolytic & 15 & 3.5 & - & - \\
\hline HZO & 15 & 8.6 & 1.8 & 8.99 \\
\hline Tuberculosis & 10 & 4 & 7.9 & - \\
\hline $\begin{array}{l}\text { Iridocyclitis } \\
\text { a/w arthritis }\end{array}$ & 5 & 7.1 & - & - \\
\hline
\end{tabular}

In the present study, majority of the cases were idiopathic in nature which corresponds with the other studies. Blunt trauma was the most common cause of anterior uveitis followed by phacolytic uveitis. This may be explained by the fact that the rural agricultural population have a greater predeliction to trauma.

Visual acuity at presentation was less than $6 / 12$ in about $50 \%$ of patients which improved after treatment to $>6 / 9$ in $80 \%$ of these cases. Visual acuity improved only marginally in the patient who had macular edema 
All the patients were treated medically and responded favourably to treatment. only 3 patients required surgical intervention in the form of cataract surgery. A few patients were lost to follow up. The average follow up period was about 2 months.

\section{Conclusions}

Anterior uveitis is a progressive disease with potentially blinding complications and sequelae. The aetiology is varied and remains unknown in majority of the cases. In all cases of anterior uveitis, posterior uveitis should be ruled out by a thorough posterior segment evaluation. A detailed systemic evaluation in these cases is important, since anterior uveitis maybe an early manifestation of an underlying systemic disease.

Ordering a standard battery of laboratory investigations leads to delay in diagnosis and excessive expenditure. Some of the investigations may not be affordable or available to the rural population. A more acceptable method would be to consider factors like age, sex, history, clinical findings and then ordering for appropriate tailored laboratory investigations.

Early diagnosis and prompt appropriate treatment results in good visual outcome. Chronicity and delay in therapy increases the risk of vision threatening complications.

\section{References}

[1] Rathinam SR.CME series. All India Ophthalmological Soceity. Uveitis made simple-Work up and management.20:1-42.

[2] Rathinam SR, Namperumalswamy P. Global variation and pattern changes in epidemiology of uveitis. Indian $\mathrm{j}$ Ophthalmol. 2007;55(3):173-183.

[3] Nussenblatt RB, WhitcupSM. Uveitis fundamentals and clinical practice. $3^{\text {rd }}$ edition. Pennysylvania (PA):Mosby;2004: $273-286$.

[4] Yanoff M, Duker JS, Augsburger JJ, Azad DT, Diamond GR, Dutton JJ et al. Ophthalmology $2^{\text {nd }}$ edition Missouri(MO):Mosby;2004:1105-1113.

[5] Power JW. Introduction to uveitis. In Albert DM , Jakobiec FA, Azar DT, Gragoudas ES, Power SM, Robinson NL. Principles and practice of Ophthalmology. $2^{\text {nd }}$ edn. Vol.2 Pennsylvania(A):WB Saunders company; 2000. p1189-1216.

[6] Venkataraman A, Rathinam SR. A pre- and post treatment of vision related quality of life in uveitis. Indian J Ophthalmol.2008;56:307-312.

[7] Duke-Elder S, Perkins ES. Diseases of the uveal tract. In: Duke-Elder S. Eds System of Ophthalmology. Vol 9. London:Henry Kimpton; 1966. p39-594.

[8] Opremack EM, Winningham ET, Foster CS, Forster D, Moorthy RS,Lopatynsky M.Basic and Clinical Science Course. San Francisco(A): American Academy of Ophthalmology; 2006.p.235-240.

[9] Dodds EM. Treatment strategies in patients with anterior uveitis. IOC 2000:39(2): p55-65.

[10] Rao NA, Forster DJ. Nonspecific therapy of Uveitis. In:Podos SM, Yanoff M, eds. Textbook of ophthalmology. Vol 2. New York: Gower Medical publishing; 1992. p3.2

[11] Kanski JJ. Clinical Ophthalmology- A systematic approach. $6^{\text {th }}$ edn. Pennsylvania(PA): Elsevier; 2007.p.441-504.

[12] Djalilian AR, Nussenblatt RB. Immunosuppression in uveitis. Ophthalmol Clin Am.2002;15:395-404.

[13] Rodriguez A, Calonge M, Pedroza-Seres M, Akova YA, Messmer EM, D’Amico DJ, et al. Referral patterns of Uveitis in a tertiary care centre.Arch Ophthalmol.1996;114:593-599.

[14] Singh R, Gupta V, Gupta A. Pattern of uveitis in a referral eye clinic in North India. Indian J Ophthalmol.2004;52:121-125.

[15] Henderly DE, Genstler AJ, Smith RE, Rao NA. Changing patterns of uveitis. Am J Ophthalmol.1987;103(2):131-136. 